\title{
Canine Adenovirus 2: A Natural Choice for Brain Circuit Dissection
}

\author{
Andréanne Lavoie ${ }^{1,2}$ and Bao-hua Liu'1,2* \\ ${ }^{1}$ Department of Biology, University of Toronto Mississauga, Mississauga, ON, Canada, ${ }^{2}$ Department of Cell and Systems \\ Biology, University of Toronto, Toronto, ON, Canada
}

Canine adenovirus-2 (CAV) is a canine pathogen that has been used in a variety of applications, from vaccines against more infectious strains of CAV to treatments for neurological disorders. With recent engineering, CAV has become a natural choice for neuroscientists dissecting the connectivity and function of brain circuits. Specifically, as a reliable genetic vector with minimal immunogenic and cytotoxic reactivity, CAV has been used for the retrograde transduction of various types of projection neurons. Consequently, CAV is particularly useful when studying the anatomy and functions of long-range projections. Moreover, combining CAV with conditional expression and transsynaptic tracing results in the ability to study circuits with cell- and/or projectiontype specificity. Lastly, with the well-documented knowledge of viral transduction, new innovations have been developed to increase the transduction efficiency of CAV and circumvent its tropism, expanding the potential of CAV for circuit analysis.

OPEN ACCESS

Edited by:

Mathieu Wolff,

Centre National de la Recherche Scientifique (CNRS), France

Reviewed by:

Sebastien Parnaudeau, INSERM U1130 Neurosciences Paris

Seine, France

Shauna L. Parkes,

Centre National de la Recherche

Scientifique (CNRS), France

*Correspondence:

Bao-hua Liu

baohua.liu@utoronto.ca

Received: 30 October 2019

Accepted: 14 January 2020

Published: 27 February 2020

Citation:

Lavoie A and Liu B (2020) Canine Adenovirus 2: A Natural Choice for Brain Circuit Dissection Front. Mol. Neurosci. 13:9. doi: 10.3389/fnmol.2020.00009
Keywords: canine adenovirus 2, neural circuit, retrograde, circuit tracing, circuit function, cell type specificity, projection specificity

\section{INTRODUCTION}

Canine adenovirus-2 (CAV) is a non-human pathogen that causes a mild infectious respiratory disease in dogs known as "kennel cough." CAV was initially studied to develop a vaccine against canine adenoviruses-1, the cause of a severe liver disease in dogs, and proposed as a long-term gene therapy vector for neurological disorders (Kremer et al., 2000; Chillon and Kremer, 2001; Soudais et al., 2001). Since then, CAV has also attracted neuroscientists because of several advantageous properties for studying the anatomy and function of neural circuits (Junyent and Kremer, 2015; del Rio et al., 2019). Specifically, it is primarily the retrograde ability of CAV to deliver cargo genes via axon terminals that allow the investigation of the pattern and function of long-range projections

\footnotetext{
Abbreviations: ACC, anterior cingulate cortex; ACtx, auditory cortex; Amy, amygdala; Ath, auditory thalamus; BLA, basolateral amygdala; BPN, basal pontine nucleus; $\mathrm{Cb}$, cerebellum; CeA, central amygdala; CLA, claustrum; CoA, cortical amygdaloid nucleus; Contra., contralateral; DBB, diagonal band of brocca; DCN, deep cerebellar nuclei; DG, dentate gyrus; DMH, dorsomedial hypothalamus; DRN, dorsal raphe nucleus; EC, entorhinal cortex; GC, gustatory cortex; HPC, hippocampus; IC, inferior colliculus; IO, inferior olive; LC, locus coeruleus; LH, lateral hypothalamus; LHb, lateral habenula; LS, lateral septum; LTDg, laterodorsal tegmentum; M1, primary motor cortex; MC, motor cortex; MdD, reticular formation; MDT, medial dorsal thalamus; Me, medulla; mPFC, medial prefrontal cortex; mPOA, medial preoptic area; NAc, nucleus accumbens; NG, nodose ganglia; NOT/DTN, complex of nucleus of optic tract and dorsal terminal nucleus; NRTP, nucleus reticularis tegmenti pontis; NTS, nucleus tractus solitaries; OB, olfactory bulb; OFC, orbitofrontal cortex; ORBvl, ventrolateral orbital cortex; PAG, periaqueductal gray; PBNl, lateral parabrachial nucleus; PCRt, parvocellular reticular formation; PFC, prefrontal cortex; PLC, prelimbic cortex; POm, posterior medial thalamic nucleus; preBötC, preBötzinger complex; PVN, hypothalamic paraventricular; PVT, paraventricular thalamus; RE, thalamic nucleus reuniens; RSP, retrosplenial cortex; SC, superior colliculus; SNc, substantia nigra pars compacta; SON, supraoptic nuclei; STN, subthalamic nucleus; TMN, tuberomammillary nucleus; VC, visual cortex; vMT, ventral midline thalamus; VTA, ventral tegmental area.
} 
(Junyent and Kremer, 2015). In addition, CAV is useful for studying neural circuits because it has a high neuronal specificity and a strong compatibility with conditional gene expression (Kremer et al., 2000; Soudais et al., 2001; Junyent and Kremer, 2015). Furthermore, CAV is a reliable vector for long-term functional studies, since it mediates stable, lasting gene expression while sustaining low immunogenicity and cytotoxicity levels (Kremer et al., 2000; Chillon and Kremer, 2001; Soudais et al., 2001). This mini-review will summarize the properties that give CAV its edge, highlighting their utility in dissecting the connectivity and functions of neural circuits.

\section{BENEFICIAL PROPERTIES OF CAV FOR CIRCUIT ANALYSIS}

Canine adenovirus-2 viruses have been widely utilized in neuroscience due to their capability of infecting axon terminals via a retrograde mechanism and then driving gene expression at the somata. Owing to this retrograde capability, when injected into a brain region, CAV viruses transduce projection neurons which innervate the injection site, in addition to neurons at the injection site (Kremer et al., 2000; Chillon and Kremer, 2001; Soudais et al., 2001; Bru et al., 2010). CAV's retrograde capability relies on the coxsackievirus and adenovirus receptor (CAR) (Kremer et al., 2000; Chillon and Kremer, 2001; Soudais et al., 2001). CAR is a cell adhesion molecule necessary for the docking, internalization, endocytosis, and axonal transport of CAV viruses (Salinas et al., 2009). This receptor is highly enriched at presynaptic sites of neurons, but exists in low density in the somata and dendrites of neurons (Zussy et al., 2016). This domain-specific CAR expression gives rise to the retrograde transport of $\mathrm{CAV}$, making it a powerful tool for mapping long-range connectivity between brain regions (Junyent and Kremer, 2015).

Another advantage of CAV for neuroscientists is that CAV vectors exhibit strong tropism, biasing neurons. For example, in the peripheral nervous system, CAV viruses preferentially transduced olfactory sensory neurons instead of the columnar epithelial cells (Bru et al., 2010). Moreover, when injected in the central nervous system, CAV strongly infects neurons but not non-neuronal types (Soudais et al., 2001; Bru et al., 2010). The molecular basis for this neuronal tropism is that CAR expression in the brain is primarily, if not exclusively, on neurons but not on astrocytes, oligodendrocytes, endothelium, or meningeal cells (Soudais et al., 2001; Persson et al., 2006). So far, in the central nervous system, CAV vectors have been successfully used to transduce various types of neurons in broad regions of the brain, demonstrating their wide applicability for studying neural circuits (Table 1). For example, CAV can transduce a variety of neurotransmitter systems, including, but not limited to, glutamatergic, dopaminergic, GABAergic, noradrenergic, oxytonergic, serotonergic, and cholinergic systems (Table 1). Furthermore, CAV has been successfully used in a broad diversity of cortical and subcortical projection pathways (Table 1). Even though rodents were used as the animal models in most of CAV applications in Table $\mathbf{1}$, recently, CAV was also successfully used in non-human primates (Table 1; Mestre-Francés et al., 2018; Bohlen et al., 2019; Dopeso-Reyes et al., 2019). These studies validate the applicability of CAV as a gene delivery tool in nonhuman primates, facilitating the investigation of neural circuits in a more human-relevant model.

Among a number of retrograde viruses (for example, rabies, lentivirus, and rAAV2-retro), what makes CAV viruses unique is their carrying capacity and physical size. In fact, CAV is the second largest retrograde virus with a $30-36 \mathrm{~kb}$ cloning capacity and $\sim 90 \mathrm{~nm}$ diameter, leading over rabies (1-3 kb) and lentivirus $(9 \mathrm{~kb}$ ) by 10 - and 3 -fold, respectively (Thompson and Towne, 2018). The large carrying load of CAV allows flexible, diverse, and creative design of cargo genes, which is particularly useful when dissecting neural circuits. For example, one can combine a variety of genes such as optogenetic tools, genetically encoded indicators of neuronal activity, fluorophores, large promoters, recombinases, LoxP/Flp sequences, and so on in one CAV vector (Figure 1A). Such combinations allow one to selectively label neurons according to cell type and/or projection, and they also facilitate efforts to monitor and perturb neural activity simultaneously (Soudais et al., 2004; Junyent and Kremer, 2015). Moreover, the large physical size of CAV provides advantages for neuroscientists performing stereotactic injections into small nuclei. CAV viruses ( $~ 90 \mathrm{~nm}$ in diameter) remain near the injection site compared to smaller adeno-associated viruses (AAV) (22 nm in diameter). For instance, $0.25-0.5 \mu \mathrm{l}$ of CAV spread on average by $200 \mu \mathrm{m}$ from the center of the injection site, while $0.25 \mu \mathrm{l}$ of rAAV2-retro spread four times more (Schwarz et al., 2015; Tervo et al., 2016). This restricted diffusion of CAV is useful when studying small structures, such as the complex of the nucleus of the optic tract and the dorsal terminal nucleus (NOT/DTN) (Liu et al., 2016), PAG (de Git et al., 2018) or CLA (Crick and Koch, 2005). It is worth noting that CAV cannot be injected with iontophoresis, which is commonly used to confine the spread of electrically charged AAV viruses (Gerhardt and Palmer, 1987), because the coat proteins of CAV are almost electrically neutral (10 times less charged than AAV viruses) (Karlin and Brendel, 1988; Chillon and Kremer, 2001).

For CAV to be an effective gene delivery tool, it should provide lasting, stable gene transduction. Indeed, to determine its viability for long-term experiments, Soudais et al. (2004) injected a CAV vector carrying green fluorescent protein (GFP) gene into multiple sites of the striatum in rats and indeed observed a high level of green fluorescent protein expression lasting for more than a year. In addition to rodents, CAV transduction led to a stable long-term transgene expression in a human stem-cell-derived 3D neural in vitro model (Simão et al., 2016), demonstrating its promise for functional experiments. Moreover, an ideal gene delivery vector should also avoid host immune responses and cytotoxicity. Indeed, CAV viruses are not human pathogens and do not induce significant cellular infiltration in rat brains (Soudais et al., 2004), nor in rhesus monkeys, unless abnormally high titers are used (Bohlen et al., 2019). Even a pre-existing immunity against human adenoviruses does not significantly affect CAV transduction (Klonjkowski et al., 1997; Kremer et al., 2000; Ibanes and Kremer, 2013). To further minimize the possible disruptions to normal neural processes caused by 
TABLE 1 | Summary of cell types and circuit pathways where CAV had been used for circuit analysis.

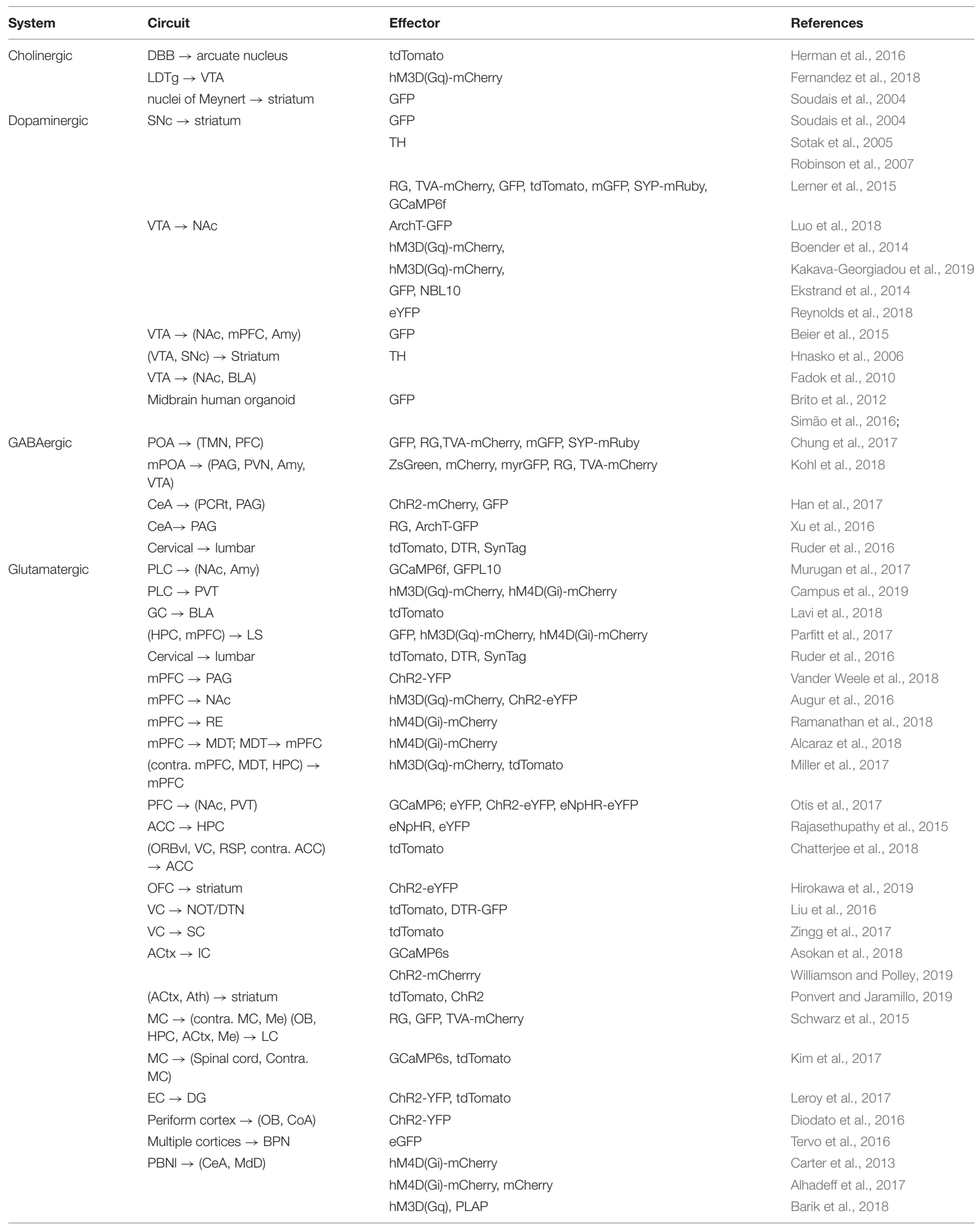


TABLE 1 | Continued

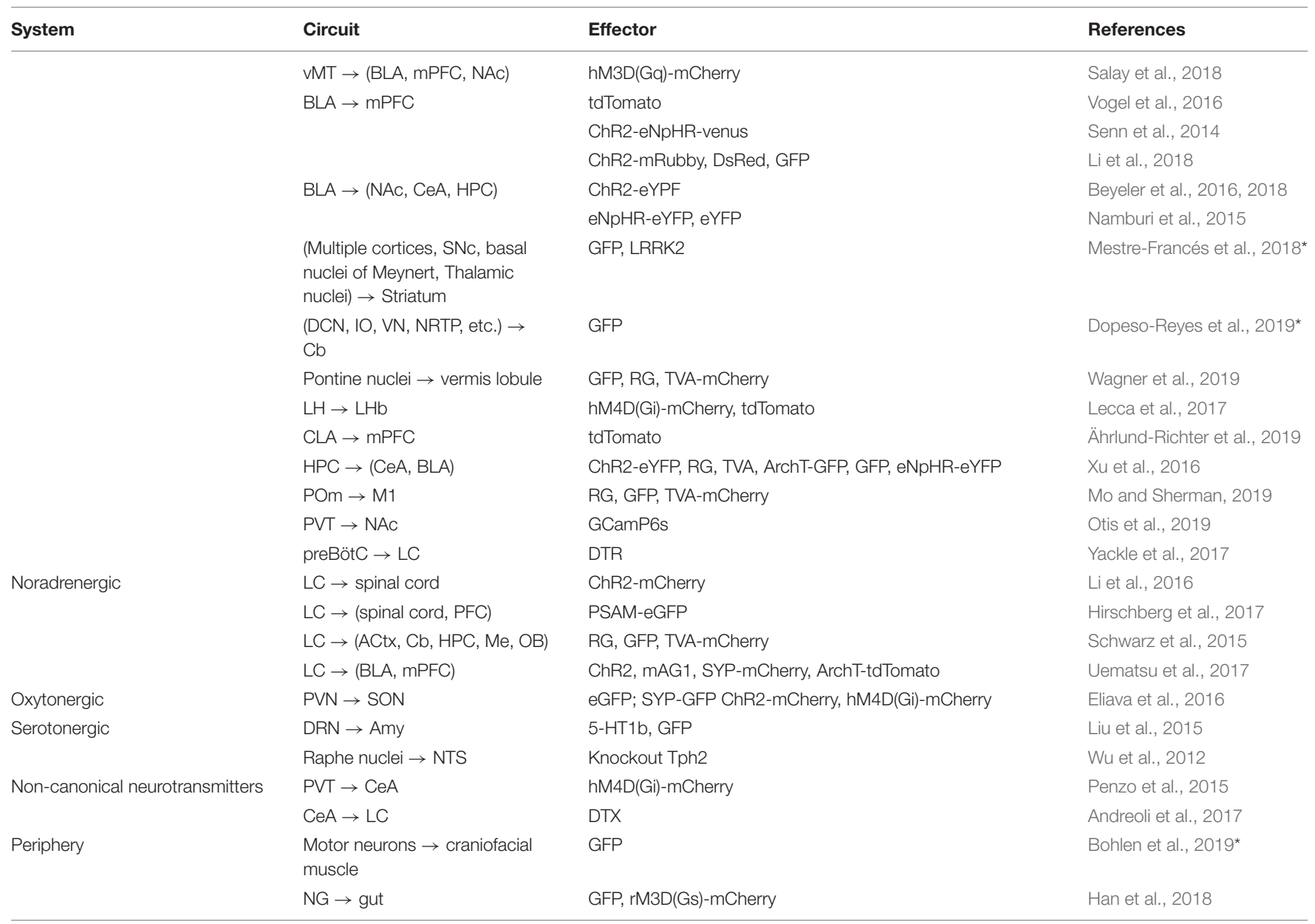

The citations in this table serve as examples of each type of studies. *Non-human primate studies.

viral infection, CAV viral vectors were further engineered. For instance, the early region 1 (E1) gene, which is important for DNA replication, was deleted from CAV genome (Klonjkowski et al., 1997). The E1-deleted CAV is replication incompetent (Chartier et al., 1996; Fernandes et al., 2013) and thus causes negligible immune response in humans, non-human primates, and rodents at experimentally relevant titers (Kremer et al., 2000; Perreau and Kremer, 2005; Bohlen et al., 2019; Lau et al., 2019). Consequently, a large number of neurons can be transduced by E1-deleted CAV without being recognized and eliminated by immune cells (Kremer et al., 2000; Soudais et al., 2004; Perreau and Kremer, 2005; Lau et al., 2019).

Another line of evidence supporting the low cytotoxicity of CAV came from studies of neuronal morphology. CAV infection did not change the shape of the somata, the axonal arborization, the number of synaptic buttons, nor did it alter the ultrastructures of transduced neurons (Simão et al., 2016; Li et al., 2018). Interestingly, even with high multiplicity of infection $(\sim 1,000$ viral genomes/cell - which is $10-50 \times$ higher than normal; Hemmi et al., 1998), CAV did not disrupt the neuronal development of cultured cells, in contrast to both AAV and lentivirus (Piersanti et al., 2013). The long-lasting gene expression and negligible impact on the physiology of neurons make CAV a competent vector when expressing effectors for functional analyses. Indeed, CAV-Cre mediated the expression of effectors for chemogenetics (Augur et al., 2016; Roth, 2016; Alcaraz et al., 2018; Ramanathan et al., 2018), genetic ablation (Liu et al., 2016), and calcium imaging (Otis et al., 2017, 2019) for an intermediate time window, ranging from 2 weeks to a couple of months. Beyond 2 months, CAV can steadily express effectors for longer term functional analysis. For examples, CAV-mediated transduction of $\mathrm{ChR} 2$ in LC neurons remained stable for 6 months and was used to manipulate the sleep-wake transition of mice (Li et al., 2016). These experiments demonstrated the applicability of CAV for studying the physiology of neural circuits, with minimal effects on cellular health and circuit integrity.

\section{APPLICATIONS}

Canine adenovirus- 2 is a powerful tool for mapping the input and output innervations of various types of projection neurons, and for recording or manipulating their activity. The simplest 


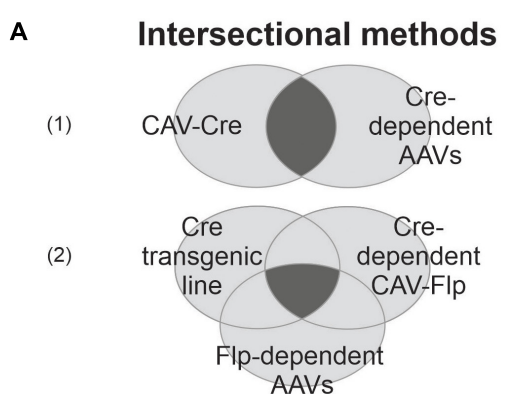

C

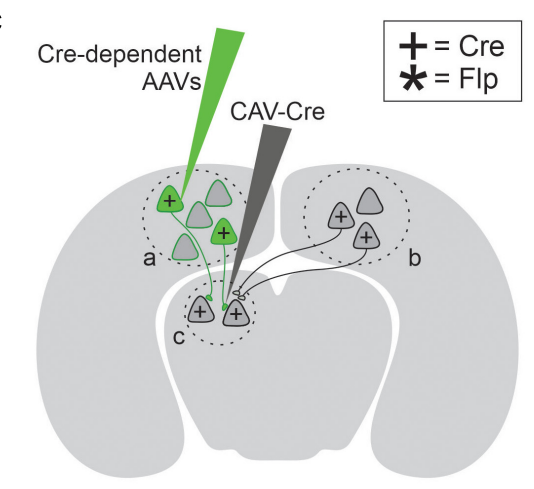

$\mathbf{E}$

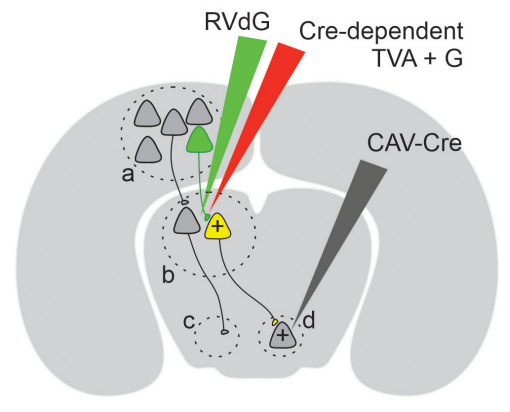

B

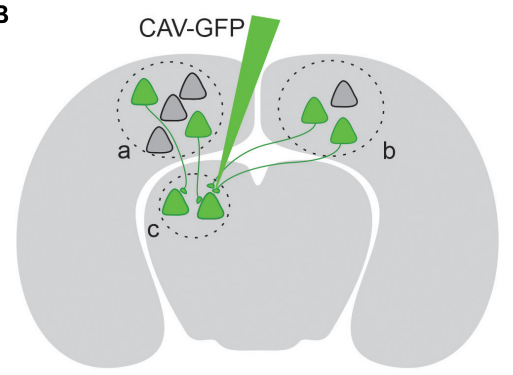

D

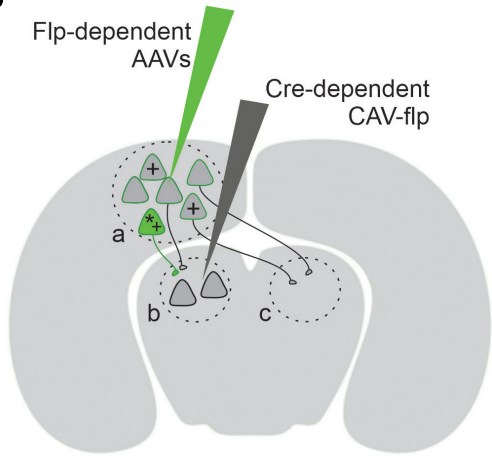

cell-type specific Cre trsangenic line

$\mathbf{F}$

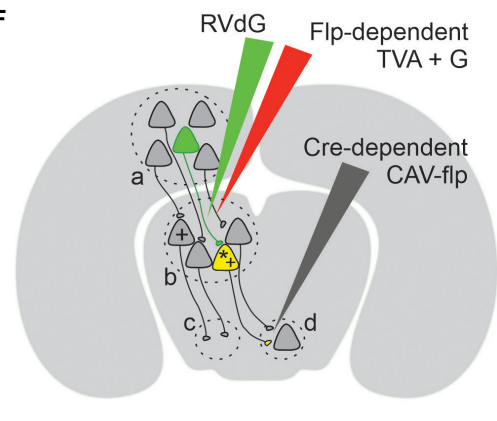

cell-type specific Cre transgenic line

FIGURE 1 | Canine adenovirus type 2 (CAV-2) combined with genetic approaches allows a variety of experimental designs for circuit analyses. (A) Venn diagram of two intersectional methods: part (A1) provides projection-specific expression using two conditions, while part (A2) provides cell-type and projection-specific expression using three conditions. (B) The simplest experimental design that labels both local (area c) and projection neurons (areas a and b). (C) The schematics of experimental designs for projection-specific expression with the help of Cre (+) recombinase. (D) The schematics of experimental designs for cell-type and projection-specific expression with the help of both Cre (+) and Flp (*) recombinases. (E) The schematics of transsynaptic experimental design which selectively labels the input onto projection-specific neuronal population defined by retrograde CAV-Cre. (F) The schematics of transsynaptic experimental design which selectively labels the input onto cell-type and projection-specific neuronal population.

application of CAV involves transducing presynaptic and local neurons with either a fluorophore or an effector (Figure 1B). For instance, Li et al. (2016) revealed the existence of two separate neuronal populations in the rodent LC by injecting CAV carrying either red or green fluorophore in one of two known postsynaptic targets of LC neurons. Similarly, this straightforward experimental design was also used in non-human primates to express fluorescent proteins in neural pathways of interest, including motor neurons that innervate craniofacial muscles and midbrain neurons that project to the $\mathrm{Cb}$ (Bohlen et al., 2019; Dopeso-Reyes et al., 2019). This simple experimental design works well to tag projection neurons innervating a target of interest. However, on its own, CAV cannot be used to selectively target a single pathway, nor to report the anatomical origin of observed fluorescent axonal fibers. This limitation arises from the ambiguity that CAV can retrogradely transduce projection neurons non-specifically in any presynaptic region, as well as neurons near the injection site through their dendrites and somata, which express low but significant levels of CAR (Bru et al., 2010; Zussy et al., 2016; Dopeso-Reyes et al., 2019) and through their local axons (Figure 1B). To remove this ambiguity, a variety of conditional gene expression paradigms 
have been developed, taking advantage of DNA recombinases (Figures 1C-F; Nagy, 2000). For instance, CAV viruses carrying the Cre recombinase gene can be injected into a target of interest, in addition to a second injection of AAV viruses carrying a target gene flanked by loxP sequences, injected into a potential presynaptic site (Figure 1C). Cre recognizes loxP and conditionally turns on (or off) the loxP-flanked target gene (Nagy, 2000). By combining CAV's retrograde capability with Cre-loxP conditional expression, this intersectional method (Figure 1A) labels specific neuronal projections (Senn et al., 2014; Penzo et al., 2015; Augur et al., 2016; Liu et al., 2016; de Git et al., 2018). This design was used to identify a corticofugal pathway from the VC to the brainstem and to ablate it exclusively (Liu et al., 2016), demonstrating the potential of CAV in projection pathway specific circuit analysis (Junyent and Kremer, 2015). The design in Figure 1C was ingeniously modified to express genes in an even more selective way (Figure 1D). In this new method, a second conditional expression system Flp-Frt (Flp, flippase recombinase; Frt, Flp recombinase target sequences) (Rodríguez et al., 2000) is added so that a Cre transgenic mouse line is used to restrict the expression of target genes in molecularly defined cell types, while Flp carried by CAV selects projection pathways. Therefore, both projection specificity and cell-type specificity are accomplished simultaneously with this clever design. This intersectional method was used in a few studies to lay out the projections of specific types of neurons (Schwarz et al., 2015; Chung et al., 2017; Kakava-Georgiadou et al., 2019). For example, Chung et al. (2017) examined the output pattern of GABAergic neurons in the preoptic area projecting to the TMN pathway.

The above intersectional strategy is not limited to the applications of mapping direct monosynaptic connections between two brain regions $(a \rightarrow b)$ (Figures 1C,D). Instead, it can also be applied to trace more complex neural circuits involving disynaptic connections $(\mathrm{a} \rightarrow \mathrm{b} \rightarrow \mathrm{c})$, with the help of EnvA-pseudotyped, glycoprotein (G)-deleted rabies viruses (RVdG) (Figures 1E,F). Wild-type rabies viruses are capable of transsynaptic transport, which allows them to move from postsynaptic neurons, via synapses, to presynaptic neurons (Wall et al., 2010). The engineered RVdG, however, loses this capability unless the target postsynaptic neurons (the so-called starter cells) express both avian sarcoma leukosis virus receptor (TVA) and G (Wall et al., 2010). TVA receptor is required for EnvA-pseudotyped rabies to enter starter cells, and G protein is necessary for rabies's transsynaptic capability (Wall et al., 2010). The expression of those two proteins in starter cells complements RVdG and allows it to infect the starter cell's presynaptic neurons (Wall et al., 2010). Making use of this elegant design, the disynaptic tracing outlined in Figures $\mathbf{1 E}, \mathbf{F}$ occurs in two steps: (1) the intersectional method detailed previously, which uses CAV-Cre to selectively express TVA and G protein in starter cells, defining the output projections $(b \rightarrow d) ;(2)$ the retrograde transsynaptic transport of RVdG determines the input innervation of starter cells $(a \rightarrow b)$. These disynaptic tracing methods have been used to determine the pattern of inputs received by individual noradrenaline populations in LC defined by their output target and cell type (Schwarz et al., 2015). This study benefited greatly from CAV's large size and low diffusion rate, which confines $\mathrm{CAV}-\mathrm{Cre}$ within the size of small brain regions of interest (Schwarz et al., 2015). In sum, CAV is most widely used to carry recombinases or recombinase-dependent constructs (Table 1), making it a powerful retrograde vector to investigate both monosynaptic and disynaptic connections within a neural circuit.

Even though most of our examples of CAV and intersectional method applications concerned circuit anatomy, the same intersectional approaches can be easily tweaked for functional analyses or molecular profiling. For instance, a variety of effector molecules have been conditionally expressed for either chemogenetics (Boender et al., 2014; Augur et al., 2016; Alcaraz et al., 2018; Fernandez et al., 2018; Ramanathan et al., 2018; Kakava-Georgiadou et al., 2019), optogenetic (Eliava et al., 2016; Li et al., 2016), projection-specific genetic ablations

TABLE 2 | Summary of cell type or projection-specific CAV tropism.

\begin{tabular}{|c|c|c|c|}
\hline System & Circuit & Comparison & References \\
\hline \multirow[t]{5}{*}{ Glutamatergic } & $\mathrm{BLA} \rightarrow \mathrm{mPFC}$ & $\begin{array}{l}\text { CAV: bias medial BLA cells } \\
\text { HSV: bias lateral BLA cells } \\
\text { Retro-beads: no bias }\end{array}$ & Senn et al., 2014 \\
\hline & (contra. ACC, ORBvl, VISal, RSP) $\rightarrow$ ACC & $\begin{array}{l}\text { CAV: bias } L 5 \text { cells } \\
\text { Retro-AAV: bias } L 2 / 3 \text { cells } \\
\text { Rabies: both } L 5 \text { and } L 2 / 3 \text { cells }\end{array}$ & Chatterjee et al., 2018 \\
\hline & Cortices $\rightarrow$ BPN & $\begin{array}{l}\text { CAV: low efficiency } \\
\text { rAAV2-retro: high efficiency } \\
\text { Fluro-Gold: high efficiency }\end{array}$ & Tervo et al., 2016 \\
\hline & $\mathrm{OFC} \rightarrow \mathrm{VS}$ & $\begin{array}{l}\text { CAV: low efficiency } \\
\text { CAV + AAV-CAR: high efficiency }\end{array}$ & Li et al., 2018 \\
\hline & $\mathrm{BLA} \rightarrow \mathrm{mPFC}$ & $\begin{array}{l}\text { CAV: low efficiency } \\
\text { CAV + AAV-CAR: high efficiency }\end{array}$ & Kakava-Georgiadou et al., 2019 \\
\hline \multirow[t]{2}{*}{ Dopaminergic } & $(\mathrm{VTA}, \mathrm{DNC}) \rightarrow \mathrm{DLS}$ & $\begin{array}{l}\text { CAV + AAV-CAR: high efficiency } \\
\text { rAAV2-retro: low efficiency }\end{array}$ & \\
\hline & $\mathrm{VTA} \rightarrow \mathrm{NAc}$ & $\begin{array}{l}\text { CAV = CAV + AAV-CAR: } \\
\text { high efficiency } \\
\text { rAAV2-retro: low efficiency }\end{array}$ & \\
\hline
\end{tabular}


(Wu et al., 2012; Liu et al., 2016), optical calcium imaging (Otis et al., 2017, 2019), and molecular profiling (Ekstrand et al., 2014). Furthermore, the ability of CAV to seamlessly deliver and selectively express effectors can be paired with classical techniques, such as slice or in vivo electrophysiology (Eliava et al., 2016; Li et al., 2016), and a variety of behavior paradigms (Liu et al., 2016; Kakava-Georgiadou et al., 2019). Pairing these techniques with CAV and intersectional methods enables a wide range of combinations, allowing substantial versatility and creativity in experimental designs. It should be noted that, regardless of the vector used, long-term overexpression of Cre recombinase can be toxic (Silver and Livingston, 2001; Braz et al., 2002; Whitsett and Perl, 2006; Gong et al., 2007; Harno et al., 2013; Janbandhu et al., 2014; Lam et al., 2019), and therefore, precautions are needed when Cre is used in functional assays.

\section{CAV LIMITATIONS AND FUTURE DIRECTIONS}

In spite of the great success of CAV in the above studies, one should be cautious of the limitations of this tool and aware of the caveats when interpreting experimental results. For instance, there is evidence that CAV transduction biases some types of neurons or pathways (Table 2), likely due to varying CAR expression level in different types of neurons (Kremer, 2004; Grove and Marsh, 2011). For example, when examining the projection from basolateral Amy (BLA) to mPFC, Senn et al. (2014) found that CAV and herpes simplex virus 1 retrogradely labeled largely non-overlapping subpopulations of BLA neurons when injected into the $\mathrm{MPFC}$ area, indicating that CAV transduced only a part of this projection population. In addition, the strong tropisms of CAV for particular cell types over others was also observed in corticocortical projections. In particular, CAV injected in the ACC of mice preferentially transduced neurons in layer 5 of the primary VC; in contrast, other retrograde viruses, such as engineered rabies and rAAV2retro, injected in the same cortical area transduced neurons across multiple layers of the primary VC (Chatterjee et al., 2018). Therefore, when using CAV to map unknown connectivity, one must be cautious when drawing conclusions about negative results, as a lack of evidence for connectivity could be alternatively explained by CAV tropism.

A second limitation of CAV is its efficacy of retrograde transduction. While sufficient to drive gene expression for both anatomical and functional experiments (Table 1), CAV viruses are not quite comparable in infectivity and retrograde transport to other retrograde viruses such as rAAV2-retro and rabies virus (Aschauer et al., 2013; Tervo et al., 2016; Chatterjee et al., 2018; Table 2). For example, in the corticopontine circuit, rAAV2-retro viruses injected into the basal pontine nuclei transduced 22 times more layer 5 projection neurons in the cortex than the CAV viruses (Tervo et al., 2016). As such, a more efficient CAV virus with little tropism would be a great improvement, since it could facilitate the detection of sparse projections and increase the strength of functional manipulations, facilitating the detection of subtle physiological or behavioral effects.
To improve the efficiency of CAV or even overcome its tropism against some neuronal types, an elegant receptor complementation strategy was recently developed, focusing on CAR, a key receptor molecule for the retrograde capability of the CAV (Li et al., 2018). In this method, the CAR receptor was virally expressed in candidate projection neurons, which in turn facilitated the retrograde transduction of those targeted neurons by CAV carrying Cre recombinase (Li et al., 2018). This strategy increased the efficacy of CAV retrograde transport in the BLA-to-mPFC pathway, where CAV has limited infectivity in control animals (Li et al., 2018). This strategy is also potentially useful to circumvent the tropism of other retrograde viruses, providing CAR/CAV combination a significant advantage over rAAV2-retro and rabies (Li et al., 2018). For example, rAAV2retro viruses showed marginal retrograde transduction of dopaminergic neurons in the VTA and SNc (VTA/SNc) that project to dorsolateral striatum (DLS) (Tervo et al., 2016). By virally expressing the CAR receptor in VTA/SNc, the number of dopaminergic neurons that were retrogradely infected by the CAV injected into the DLS was approximately nine times larger than when rAAV2-retro was used. Nevertheless, the applicability and limitations of this receptor complementation strategy in other cell types and pathways need to be explored and validated (Kakava-Georgiadou et al., 2019).

\section{CONCLUSION}

In summary, the unique characteristics of CAV make it an intriguing choice for neuroscientists. CAV vectors complement the toolbox of retrograde viruses, which can be used to reveal the connectivity and physiology of neural circuits. In particular, due to low toxicity, minimal immunogenicity, and stable gene expression, CAV is ideal for long-term functional analyses of brain circuits. Moreover, the capability of combining CAV with conditional expression and transsynaptic tracing makes it a promising tool to study circuits in cell- and/or projectiontype specific manners. Finally, the success of the CAR receptor complementation strategy provides a method to circumvent the limitations of CAV, opening a new era for circuit analysis. Needless to say, CAV will continue to facilitate the long-standing quest to ultimately understand the biological substrates and logics of brain functions.

\section{AUTHOR CONTRIBUTIONS}

Both authors contributed to the writing and figure design.

\section{FUNDING}

Work in the authors' laboratory was supported by the Canadian Foundation of Innovation and Ontario Research Fund (CFI/ORF project no. 37597), NSERC (RGPIN-2019-06479), Research and Scholarly Activity Fund, and Connaught New Researcher Awards. 


\section{REFERENCES}

Ährlund-Richter, S., Xuan, Y., van Lunteren, J. A., Kim, H., Ortiz, C., Dorocic, I. P., et al. (2019). A whole-brain atlas of monosynaptic input targeting four different cell types in the medial prefrontal cortex of the mouse. Nat. Neurosci. 22, 657-668. doi: 10.1038/s41593-019-0354-y

Alcaraz, F., Fresno, V., Marchand, A. R., Kremer, E. J., Coutureau, E., and Wolff, M. (2018). Thalamocortical and corticothalamic pathways differentially contribute to goal-directed behaviors in the rat. eLife 7:e32517.

Alhadeff, A. L., Holland, R. A., Zheng, H., Rinaman, L., Grill, H. J., and De Jonghe, B. C. (2017). Excitatory hindbrain-forebrain communication is required for cisplatin-induced anorexia and weight loss. J. Neurosci. 37, 362-370. doi: 10. 1523/jneurosci.2714-16.2016

Andreoli, M., Marketkar, T., and Dimitrov, E. (2017). Contribution of amygdala CRF neurons to chronic pain. Exp. Neurol. 298, 1-12. doi: 10.1016/j.expneurol. 2017.08.010

Aschauer, D. F., Kreuz, S., and Rumpel, S. (2013). Analysis of transduction efficiency, tropism and axonal transport of AAV serotypes 1, 2, 5, 6, 8 and 9 in the mouse brain. PLoS One 8:e76310. doi: 10.1371/journal.pone.0076310

Asokan, M. M., Williamson, R. S., Hancock, K. E., and Polley, D. B. (2018). Sensory overamplification in layer 5 auditory corticofugal projection neurons following cochlear nerve synaptic damage. Nat. Commun. 9:2468. doi: 10.1038/s41467018-04852-y

Augur, I. F., Wyckoff, A. R., Aston-Jones, G., Kalivas, P. W., and Peters, J. (2016). Chemogenetic activation of an extinction neural circuit reduces cue-induced reinstatement of cocaine seeking. J. Neurosci. 36, 10174-10180. doi: 10.1523/ jneurosci.0773-16.2016

Barik, A., Thompson, J. H., Seltzer, M., Ghitani, N., and Chesler, A. T. (2018). A brainstem-spinal circuit controlling nocifensive behavior. Neuron 100, 14911503.

Beier, K. T., Steinberg, E. E., DeLoach, K. E., Xie, S., Miyamichi, K., Schwarz, L., et al. (2015). Circuit architecture of VTA dopamine neurons revealed by systematic input-output mapping. Cell 162, 622-634. doi: 10.1016/j.cell.2015. 07.015

Beyeler, A., Chang, C. J., Silvestre, M., Lévêque, C., Namburi, P., Wildes, C. P., et al. (2018). Organization of valence-encoding and projection-defined neurons in the basolateral amygdala. Cell Rep. 22, 905-918. doi: 10.1016/j.celrep.2017.12. 097

Beyeler, A., Namburi, P., Glober, G. F., Simonnet, C., Calhoon, G. G., Conyers, G. F., et al. (2016). Divergent routing of positive and negative information from the amygdala during memory retrieval. Neuron 90, 348-361. doi: 10.1016/j. neuron.2016.03.004

Boender, A. J., de Jong, J. W., Boekhoudt, L., Luijendijk, M. C., van der Plasse, G., and Adan, R. A. (2014). Combined use of the canine adenovirus-2 and DREADD-technology to activate specific neural pathways in vivo. PLoS One 9:e95392. doi: 10.1371/journal.pone.0095392

Bohlen, M. O., El-Nahal, H. G., and Sommer, M. A. (2019). Transduction of craniofacial motoneurons following intramuscular injections of canine adenovirus type-2 (CAV-2) in rhesus macaques. Front. Neuroanat. 13:84. doi: 10.3389/fnana.2019.00084

Braz, J. M., Rico, B., and Basbaum, A. I. (2002). Transneuronal tracing of diverse CNS circuits by Cre-mediated induction of wheat germ agglutinin in transgenic mice. Proc. Natl. Acad. Sci. U.S.A. 99, 15148-15153. doi: 10.1073/ pnas. 222546999

Brito, C., Simão, D., Costa, I., Malpique, R., Pereira, C. I., Fernandes, P., et al. (2012). Generation and genetic modification of 3D cultures of human dopaminergic neurons derived from neural progenitor cells. Methods 56, 452460. doi: 10.1016/j.ymeth.2012.03.005

Bru, T., Salinas, S., and Kremer, E. J. (2010). An update on canine adenovirus type 2 and its vectors. Viruses 2, 2134-2153. doi: 10.3390/v2092134

Campus, P., Covelo, I. R., Kim, Y., Parsegian, A., Kuhn, B., Lopez, S. A., et al. (2019). The paraventricular thalamus is a critical mediator of top-down control of cue-motivated behavior. bioRxiv [Preprint]. doi: 10.1101/637702

Carter, M. E., Soden, M. E., Zweifel, L. S., and Palmiter, R. D. (2013). Genetic identification of a neural circuit that suppresses appetite. Nature 503, 111-141.

Chartier, C., Degryse, E., Gantzer, M., Dieterle, A., Pavirani, A., and Mehtali, M. (1996). Efficient generation of recombinant adenovirus vectors by homologous recombination in Escherichia coli. J. Virol. 70, 4805-4810. doi: 10.1128/jvi.70.7. 4805-4810.1996

Chatterjee, S., Sullivan, H. A., MacLennan, B. J., Xu, R., Hou, Y., Lavin, T. K., et al. (2018). Nontoxic, double-deletion-mutant rabies viral vectors for retrograde targeting of projection neurons. Nat. Neurosci. 21, 638-646. doi: 10.1038/ s41593-018-0091-7

Chillon, M., and Kremer, E. J. (2001). Trafficking and propagation of canine adenovirus vectors lacking a known integrin-interacting motif. Hum. Gen. Ther. 12, 1815-1823. doi: 10.1089/104303401750476302

Chung, S., Weber, F., Zhong, P., Tan, C. L., Nguyen, T. N., Beier, K. T., et al. (2017). Identification of preoptic sleep neurons using retrograde labelling and gene profiling. Nature 545, 477-481. doi: 10.1038/nature22350

Crick, F. C., and Koch, C. (2005). What is the function of the claustrum? Philos. Trans. R. Soc. Lond. B Biol. Sci. 360, 1271-1279. doi: 10.1098/rstb.2005.1661

de Git, K. C., van Tuijl, D. C., Luijendijk, M. C., Wolterink-Donselaar, I. G., Ghanem, A., Conzelmann, K. K., et al. (2018). Anatomical projections of the dorsomedial hypothalamus to the periaqueductal grey and their role in thermoregulation: a cautionary note. Physiol. Rep. 6:e13807. doi: 10.14814/ phy2.13807

del Rio, D., Beucher, B., Lavigne, M., Wehbi, A., Gonzalez-Dopeso Reyes, I., Saggio, I., et al. (2019). CAV-2 vector development and gene transfer in the central and peripheral nervous systems. Front. Mol. Neurosci. 12:71. doi: 10.3389/fnmol. 2019.00071

Diodato, A., De Brimont, M. R., Yim, Y. S., Derian, N., Perrin, S., Pouch, J., et al. (2016). Molecular signatures of neural connectivity in the olfactory cortex. Nat. Commun. 7:12238. doi: 10.1038/ncomms1223

Dopeso-Reyes, I. G., Junyent, F., Mestre-Francés, N., Whebi, A., Beucher, B., and Kremer, E. J. (2019). Identification of cerebellar afferent projections in a nonhuman primate using CAV-2 vectors. bioRxiv [Preprint]. doi: 10.1101/ 728709

Ekstrand, M. I., Nectow, A. R., Knight, Z. A., Latcha, K. N., Pomeranz, L. E., and Friedman, J. M. (2014). Molecular profiling of neurons based on connectivity. Cell 157, 1230-1242. doi: 10.1016/j.cell.2014.03.059

Eliava, M., Melchior, M., Knobloch-Bollmann, H. S., Wahis, J., da Silva Gouveia, M., et al. (2016). A new population of parvocellular oxytocin neurons controlling magnocellular neuron activity and inflammatory pain processing. Neuron 89, 1291-1304. doi: 10.1016/j.neuron.2016.01.041

Fadok, J. P., Darvas, M., Dickerson, T. M., and Palmiter, R. D. (2010). Longterm memory for pavlovian fear conditioning requires dopamine in the nucleus accumbens and basolateral amygdala. PLoS One 5:e12751. doi: 10.1371/journal. pone. 0012751

Fernandes, P., Santiago, V. M., Rodrigues, A. F., Tomás, H., Kremer, E. J., Alves, P. M., et al. (2013). Impact of E1 and Cre on adenovirus vector amplification: developing MDCK CAV-2-E1 and E1-Cre transcomplementing cell lines. PLoS One 8:e60342. doi: 10.1371/journal.pone.0060342

Fernandez, S. P., Broussot, L., Marti, F., Contesse, T., Mouska, X., Soiza-Reilly, M., et al. (2018). Mesopontine cholinergic inputs to midbrain dopamine neurons drive stress-induced depressive-like behaviors. Nat. Commun. 9:4449. doi: 10 . 1038/s41467-018-0680

Gerhardt, G. A., and Palmer, M. R. (1987). Characterization of the techniques of pressure ejection and microiontophoresis using in vivo electrochemistry. J. Neurosci. Methods 22, 147-159. doi: 10.1016/0165-0270(87)90009-4

Gong, S., Doughty, M., Harbaugh, C. R., Cummins, A., Hatten, M. E., Heintz, N., et al. (2007). Targeting Cre recombinase to specific neuron populations with bacterial artificial chromosome constructs. J. Neurosci. 27, 9817-9823. doi: 10.1523/jneurosci.2707-07.2007

Grove, J., and Marsh, M. (2011). The cell biology of receptor-mediated virus entry. J. Cell Biol. 195, 1071-1082. doi: 10.1083/jcb.201108131

Han, W., Tellez, L. A., Perkins, M. H., Perez, I. O., Qu, T., Ferreira, J., et al. (2018) A neural circuit for gut-induced reward. Cell 175, 665-678.

Han, W., Tellez, L. A., Rangel, M. J. Jr., Motta, S. C., Zhang, X., Perez, I. O., et al. (2017). Integrated control of predatory hunting by the central nucleus of the amygdala. Cell 168, 311-324.

Harno, E., Cottrell, E. C., and White, A. (2013). Metabolic pitfalls of CNS Cre-based technology. Cell Metab. 18, 21-28. doi: 10.1016/j.cmet.2013.05.019

Hemmi, S., Geertsen, R., Mezzacasa, A., Peter, I., and Dummer, R. (1998). The presence of human coxsackievirus and adenovirus receptor is associated with 
efficient adenovirus-mediated transgene expression in human melanoma cell cultures. Hum. Gene Ther. 9, 2363-2373. doi: 10.1089/hum.1998.9.16-2363

Herman, A. M., Ortiz-Guzman, J., Kochukov, M., Herman, I., Quast, K. B., Patel, J. M., et al. (2016). A cholinergic basal forebrain feeding circuit modulates appetite suppression. Nature 538, 253-256. doi: 10.1038/nature19789

Hirokawa, J., Vaughan, A., Masset, P., Ott, T., and Kepecs, A. (2019). Frontal cortex neuron types categorically encode single decision variables. Nature 576, 446-451. doi: 10.1038/s41586-019-1816-9

Hirschberg, S., Li, Y., Randall, A., Kremer, E. J., and Pickering, A. E. (2017). Functional dichotomy in spinal-vs prefrontal-projecting locus coeruleus modules splits descending noradrenergic analgesia from ascending aversion and anxiety in rats. eLife 6:e29808.

Hnasko, T. S., Perez, F. A., Scouras, A. D., Stoll, E. A., Gale, S. D., Luquet, S., et al. (2006). Cre recombinase-mediated restoration of nigrostriatal dopamine in dopamine-deficient mice reverses hypophagia and bradykinesia. Proc. Natl. Acad. Sci. U.S.A. 103, 8858-8863. doi: 10.1073/pnas.0603081103

Ibanes, S., and Kremer, E. J. (2013). Canine adenovirus type 2 vector generation via I-Sce1-mediated intracellular genome release. PLoS One 8:e71032. doi: 10.1371/ journal.pone.0071

Janbandhu, V. C., Moik, D., and Fassler, R. (2014). Cre recombinase induces DNA damage and tetraploidy in the absence of loxP sites. Cell Cycle 13, 462-470. doi: $10.4161 /$ cc. 27271

Junyent, F., and Kremer, E. J. (2015). CAV-2-why a canine virus is a neurobiologist's best friend. Curr. Opin. Pharmacol. 24, 86-93. doi: 10.1016/j. coph.2015.08.004

Kakava-Georgiadou, N., Zwartkruis, M. M., Bullich-Vilarrubias, C., Luijendijk, M., Garner, K. M., van der Plasse, G., et al. (2019). An intersectional approach to target neural circuits with cell-and projection-type specificity: validation in the mesolimbic dopamine system. Front. Mol. Neurosci. 12:49. doi: 10.3389/fnmol. 2019.00049

Karlin, S., and Brendel, V. (1988). Charge configurations in viral proteins. Proc. Natl. Acad. Sci. U.S.A. 85, 9396-9400. doi: 10.1073/pnas.85.24.9396

Kim, J., Hughes, E. G., Shetty, A. S., Arlotta, P., Goff, L. A., Bergles, D. E., et al. (2017). Changes in the excitability of neocortical neurons in a mouse model of amyotrophic lateral sclerosis are not specific to corticospinal neurons and are modulated by advancing disease. J. Neurosci. 37, 9037-9053. doi: 10.1523/ jneurosci.0811-17.2017

Klonjkowski, B., Gilardi-Hebenstreit, P., Hadchouel, J., Randrianarison, V., Boutin, S., Yeh, P., et al. (1997). A recombinant E1-deleted canine adenoviral vector capable of transduction and expression of a transgene in human-derived cells and in vivo. Hum. Gene Ther. 8, 2103-2115. doi: 10.1089/hum.1997.8.17-2103

Kohl, J., Babayan, B. M., Rubinstein, N. D., Autry, A. E., Marin-Rodriguez, B., Kapoor, V., et al. (2018). Functional circuit architecture underlying parental behaviour. Nature 556, 326-331. doi: 10.1038/s41586-018-0027-0

Kremer, E. J. (2004). CAR chasing: canine adenovirus vectors - all bite and no bark? J. Gene Med. 6, 139-151.

Kremer, E. J., Boutin, S., Chillon, M., and Danos, O. (2000). Canine adenovirus vectors: an alternative for adenovirus-mediated gene transfer. J. Virol. 74, 505-512. doi: 10.1128/jvi.74.1.505-512.2000

Lam, P. T., Padula, S. L., Hoang, T. V., Poth, J. E., Liu, L., Liang, C., et al. (2019). Considerations for the use of Cre recombinase for conditional gene deletion in the mouse lens. Hum. Genomics 13:10. doi: 10.1186/s40246-019-0192-8

Lau, A. A., Hopwood, J. J., and Hemsley, K. M. (2019). Canine adenoviral vectormediated gene transfer to the guinea pig brain. Gene Rep. 16:100432. doi: 10.1016/j.genrep.2019.100432

Lavi, K., Jacobson, G. A., Rosenblum, K., and Lüthi, A. (2018). Encoding of conditioned taste aversion in cortico-amygdala circuits. Cell Rep. 24, 278-283. doi: 10.1016/j.celrep.2018.06.053

Lecca, S., Meye, F. J., Trusel, M., Tchenio, A., Harris, J., Schwarz, M. K., et al. (2017). Aversive stimuli drive hypothalamus-to-habenula excitation to promote escape behavior. eLife 6:e30697. doi: 10.7554/eLife.30697

Lerner, T. N., Shilyansky, C., Davidson, T. J., Evans, K. E., Beier, K. T., Zalocusky, K. A., et al. (2015). Intact-brain analyses reveal distinct information carried by SNc dopamine subcircuits. Cell 162, 635-647. doi: 10.1016/j.cell.2015. 07.014

Leroy, F., Brann, D. H., Meira, T., and Siegelbaum, S. A. (2017). Input-timingdependent plasticity in the hippocampal CA2 region and its potential role in social memory. Neuron $95,1089-1102$.
Li, S. J., Vaughan, A., Sturgill, J. F., and Kepecs, A. (2018). A viral receptor complementation strategy to overcome CAV-2 tropism for efficient retrograde targeting of neurons. Neuron 98, 905-917.

Li, Y., Hickey, L., Perrins, R., Werlen, E., Patel, A. A., Hirschberg, S., et al. (2016). Retrograde optogenetic characterization of the pontospinal module of the locus coeruleus with a canine adenoviral vector. Brain Res. 1641, 274-290. doi: 10.1016/j.brainres.2016.02.023

Liu, B. H., Huberman, A. D., and Scanziani, M. (2016). Cortico-fugal output from visual cortex promotes plasticity of innate motor behaviour. Nature 538, 383-387. doi: 10.1038/nature19818

Liu, Y., Kelly, M. A., Sexton, T. J., and Neumaier, J. F. (2015). 5-HT1B autoreceptors differentially modulate the expression of conditioned fear in a circuit-specific manner. Neuroscience 298, 436-447. doi: 10.1016/j.neuroscience.2015.04.032

Luo, R., Uematsu, A., Weitemier, A., Aquili, L., Koivumaa, J., McHugh, T. J., et al. (2018). A dopaminergic switch for fear to safety transitions. Nat. Commun. 9:2483. doi: 10.1038/s41467-018-04784-7

Mestre-Francés, N., Serratrice, N., Gennetier, A., Devau, G., Cobo, S., Trouche, S. G., et al. (2018). Exogenous LRRK2G2019S induces parkinsonian-like pathology in a nonhuman primate. JCI Insight 3:e98202.

Miller, O. H., Bruns, A., Ammar, I. B., Mueggler, T., and Hall, B. J. (2017). Synaptic regulation of a thalamocortical circuit controls depression-related behavior. Cell Rep. 20, 1867-1880. doi: 10.1016/j.celrep.2017.08.002

Mo, C., and Sherman, S. M. (2019). A sensorimotor pathway via higher-order thalamus. J. Neurosci. 39, 692-704. doi: 10.1523/jneurosci.1467-18.2018

Murugan, M., Jang, H. J., Park, M., Miller, E. M., Cox, J., Taliaferro, J. P., et al. (2017). Combined social and spatial coding in a descending projection from the prefrontal cortex. Cell 171, 1663-1677.

Nagy, A. (2000). Cre recombinase: the universal reagent for genome tailoring. Genesis 26, 99-109. doi: 10.1002/(sici)1526-968x(200002)26:2<99::aid-gene1> 3.0.co; 2 -b

Namburi, P., Beyeler, A., Yorozu, S., Calhoon, G. G., Halbert, S. A., Wichmann, R., et al. (2015). A circuit mechanism for differentiating positive and negative associations. Nature 520, 675-678. doi: 10.1038/nature14366

Otis, J. M., Namboodiri, V. M., Matan, A. M., Voets, E. S., Mohorn, E. P., Kosyk, O., et al. (2017). Prefrontal cortex output circuits guide reward seeking through divergent cue encoding. Nature 543, 103-107. doi: 10.1038/nature21376

Otis, J. M., Zhu, M., Namboodiri, V. M., Cook, C. A., Kosyk, O., Matan, A. M., et al. (2019). Paraventricular thalamus projection neurons integrate cortical and hypothalamic signals for Cue-reward processing. Neuron 103, 423-431.

Parfitt, G. M., Nguyen, R., Bang, J. Y., Aqrabawi, A. J., Tran, M. M., Seo, D. K., et al. (2017). Bidirectional control of anxiety-related behaviors in mice: role of inputs arising from the ventral hippocampus to the lateral septum and medial prefrontal cortex. Neuropsychopharmacology 42, 1715-1728. doi: 10.1038/npp. 2017.56

Penzo, M. A., Robert, V., Tucciarone, J., De Bundel, D., Wang, M., Van Aelst, L., et al. (2015). The paraventricular thalamus controls a central amygdala fear circuit. Nature 519, 455-459. doi: 10.1038/nature13978

Perreau, M., and Kremer, E. J. (2005). Frequency, proliferation, and activation of human memory $\mathrm{T}$ cells induced by a nonhuman adenovirus. J. Virol. 79, 14595-14605. doi: 10.1128/jvi.79.23.14595-14605.2005

Persson, A., Fan, X., Widegren, B., and Englund, E. (2006). Cell type-and regiondependent coxsackie adenovirus receptor expression in the central nervous system. J. Neurooncol. 78, 1-6. doi: 10.1007/s11060-005-9055-3

Piersanti, S., Astrologo, L., Licursi, V., Costa, R., Roncaglia, E., Gennetier, A., et al. (2013). Differentiated neuroprogenitor cells incubated with human or canine adenovirus, or lentiviral vectors have distinct transcriptome profiles. PLoS One 8:e69808. doi: 10.1371/journal.pone.0069808

Ponvert, N. D., and Jaramillo, S. (2019). Auditory thalamostriatal and corticostriatal pathways convey complementary information about sound features. J. Neurosci. 39, 271-280. doi: 10.1523/jneurosci.1188-18.2018

Rajasethupathy, P., Sankaran, S., Marshel, J. H., Kim, C. K., Ferenczi, E., Lee, S. Y., et al. (2015). Projections from neocortex mediate top-down control of memory retrieval. Nature 526, 653-659. doi: 10.1038/nature15389

Ramanathan, K. R., Jin, J., Giustino, T. F., Payne, M. R., and Maren, S. (2018). Prefrontal projections to the thalamic nucleus reuniens mediate fear extinction. Nat. Commun. 9:4527. doi: 10.1038/s41467-018-06970-z

Reynolds, L. M., Pokinko, M., Torres-Berrío, A., Cuesta, S., Lambert, L. C., Pellitero, E. D. C., et al. (2018). DCC receptors drive prefrontal cortex 
maturation by determining dopamine axon targeting in adolescence. Biol. Psychiatry 83, 181-192. doi: 10.1016/j.biopsych.2017.06.009

Robinson, S., Rainwater, A. J., Hnasko, T. S., and Palmiter, R. D. (2007). Viral restoration of dopamine signaling to the dorsal striatum restores instrumental conditioning to dopamine-deficient mice. Psychopharmacology 191, 567-578. doi: 10.1007/s00213-006-0579-9

Rodríguez, C. I., Buchholz, F., Galloway, J., Sequerra, R., Kasper, J., Ayala, R., et al. (2000). High-efficiency deleteter mice show that FLPe is an alternative to Cre-loxP. Nat. Genet. 25, 139-140. doi: 10.1038/75973

Roth, B. (2016). DREADDs for neuroscientists. Neuron 89, 683-694. doi: 10.1016/ j.neuron.2016.01.040

Ruder, L., Takeoka, A., and Arber, S. (2016). Long-distance descending spinal neurons ensure quadrupedal locomotor stability. Neuron 92, 1063-1078. doi: 10.1016/j.neuron.2016.10.032

Salay, L. D., Ishiko, N., and Huberman, A. D. (2018). A midline thalamic circuit determines reactions to visual threat. Nature 557, 183-189. doi: 10.1038/ s41586-018-0078-2

Salinas, S., Bilsland, L. G., Henaff, D., Weston, A. E., Keriel, A., Schiavo, G., et al. (2009). CAR-associated vesicular transport of an adenovirus in motor neuron axons. PLoS Pathog. 5:e1000442. doi: 10.1371/journal.ppat.1000442

Schwarz, L. A., Miyamichi, K., Gao, X. J., Beier, K. T., Weissbourd, B., DeLoach, K. E., et al. (2015). Viral-genetic tracing of the input-output organization of a central noradrenaline circuit. Nature 524, 88-92. doi: 10.1038/nature 14600

Senn, V., Wolff, S. B., Herry, C., Grenier, F., Ehrlich, I., Gründemann, J., et al. (2014). Long-range connectivity defines behavioral specificity of amygdala neurons. Neuron 81, 428-437. doi: 10.1016/j.neuron.2013.11.006

Silver, D. P., and Livingston, D. M. (2001). Self-excising retroviral vectors encoding the Cre recombinase overcome Cre-mediated cellular toxicity. Mol. Cell 8, 233-243. doi: 10.1016/s1097-2765(01)00295-7

Simão, D., Pinto, C., Fernandes, P., Peddie, C. J., Piersanti, S., Collinson, L. M., et al. (2016). Evaluation of helper-dependent canine adenovirus vectors in a $3 \mathrm{D}$ human CNS model. Gene Ther. 23, 86-94. doi: 10.1038/gt.2015.75

Sotak, B. N., Hnasko, T. S., Robinson, S., Kremer, E. J., and Palmiter, R. D. (2005). Dysregulation of dopamine signaling in the dorsal striatum inhibits feeding. Brain Res. 1061, 88-96. doi: 10.1016/j.brainres.2005.08.053

Soudais, C., Boutin, S., and Kremer, E. J. (2001). Characterization of cis-acting sequences involved in canine adenovirus packaging. Mol. Ther. 3, 631-640. doi: $10.1006 / \mathrm{mthe} .2001 .0263$

Soudais, C., Skander, N., and Kremer, E. J. (2004). Long-term in vivo transduction of neurons throughout the rat CNS using novel helper-dependent CAV-2 vectors. FASEB J. 18, 391-393. doi: 10.1096/fj.03-0438fje

Tervo, D. G. R., Hwang, B. Y., Viswanathan, S., Gaj, T., Lavzin, M., Ritola, K. D., et al. (2016). A designer AAV variant permits efficient retrograde access to projection neurons. Neuron 92, 372-382. doi: 10.1016/j.neuron.2016.09.021

Thompson, K. R., and Towne, C. (2018). "A hitchhiker's guide to the selection of viral vectors for optogenetic studies," in Optogenetics: A Roadmap, ed. A. Stroh, (New York, NY: Humana Press), 1-23. doi: 10.1007/978-1-4939-7417-7_1

Uematsu, A., Tan, B. Z., Ycu, E. A., Cuevas, J. S., Koivumaa, J., Junyent, F., et al. (2017). Modular organization of the brainstem noradrenaline system coordinates opposing learning states. Nat. Neurosci. 20, 1602-1611. doi: 10. $1038 / \mathrm{nn} .4642$

Vander Weele, C. M., Siciliano, C. A., Matthews, G. A., Namburi, P., Izadmehr, E. M., Espinel, I. C., et al. (2018). Dopamine enhances signal-to-noise ratio in cortical-brainstem encoding of aversive stimuli. Nature 563, 397-401. doi: 10.1038/s41586-018-0682-1

Vogel, E., Krabbe, S., Gründemann, J., Cusulin, J. I. W., and Lüthi, A. (2016). Projection-specific dynamic regulation of inhibition in amygdala microcircuits. Neuron 91, 644-651. doi: 10.1016/j.neuron.2016.06.036

Wagner, M. J., Kim, T. H., Kadmon, J., Nguyen, N. D., Ganguli, S., Schnitzer, M. J., et al. (2019). Shared cortex-cerebellum dynamics in the execution and learning of a motor task. Cell 177, 669-682.

Wall, N. R., Wickersham, I. R., Cetin, A., De La Parra, M., and Callaway, E. M. (2010). Monosynaptic circuit tracing in vivo through Cre-dependent targeting and complementation of modified rabies virus. Proc. Natl. Acad. Sci. U.S.A. 107, 21848-21853. doi: 10.1073/pnas.1011756107

Whitsett, J. A., and Perl, A. K. T. (2006). Conditional control of gene expression in the respiratory epithelium: a cautionary note. Am. J. Respir. Cell. Mol. Biol. 34, 519-520. doi: $10.1165 / \mathrm{rcmb} . \mathrm{f} 310$

Williamson, R. S., and Polley, D. B. (2019). Parallel pathways for sound processing and functional connectivity among layer 5 and 6 auditory corticofugal neurons. eLife 8:e42974.

Wu, Q., Clark, M. S., and Palmiter, R. D. (2012). Deciphering a neuronal circuit that mediates appetite. Nature 483, 594-597. doi: 10.1038/nature10899

Xu, C., Krabbe, S., Gründemann, J., Botta, P., Fadok, J. P., Osakada, F., et al. (2016). Distinct hippocampal pathways mediate dissociable roles of context in memory retrieval. Cell 167, 961-972.

Yackle, K., Schwarz, L. A., Kam, K., Sorokin, J. M., Huguenard, J. R., Feldman, J. L., et al. (2017). Breathing control center neurons that promote arousal in mice. Science 355, 1411-1415. doi: 10.1126/science.aai7984

Zingg, B., Chou, X. L., Zhang, Z. G., Mesik, L., Liang, F., Tao, H. W., et al. (2017). AAV-mediated anterograde transsynaptic tagging: mapping corticocollicular input-defined neural pathways for defense behaviors. Neuron 93, 33-47. doi: 10.1016/j.neuron.2016.11.045

Zussy, C., Loustalot, F., Junyent, F., Gardoni, F., Bories, C., Valero, J., et al. (2016). Coxsackievirus adenovirus receptor loss impairs adult neurogenesis, synapse content, and hippocampus plasticity. J. Neurosci. 36, 9558-9571. doi: 10.1523/ jneurosci.0132-16.2016

Conflict of Interest: The authors declare that the research was conducted in the absence of any commercial or financial relationships that could be construed as a potential conflict of interest.

Copyright (c) 2020 Lavoie and Liu. This is an open-access article distributed under the terms of the Creative Commons Attribution License (CC BY). The use, distribution or reproduction in other forums is permitted, provided the original author(s) and the copyright owner(s) are credited and that the original publication in this journal is cited, in accordance with accepted academic practice. No use, distribution or reproduction is permitted which does not comply with these terms. 